\title{
PROPAGAÇÃO VEGETATIVA DE JASMIM-AMARELO (Jasminum mesnyi Hance) VIA ESTAQUIA
}

\section{VEGETATIVE PROPAGATION OF YELLOW JASMINE (Jasminum mesnyi Hance) BY CUTTINGS}

\author{
Claudia Tatiana Araujo da CRUZ-SILVA \\ Fernanda Pereira FANTI ${ }^{2}$ \\ Katia Christina ZUFFELLATO-RIBAS ${ }^{3}$
}

\section{RESUMO}

O jasmim-amarelo (Jasminum mesnyi Hance), pertencente à família Oleaceae, é um arbusto semiherbáceo, cujas flores, amarelas e bastante perfumadas, aparecem em abundância na primavera. Em razão do potencial ornamental da espécie esse trabalho objetivou avaliar a melhor concentração de ácido indolbutírico (AIB) para a indução do enraizamento de estacas herbáceas de jasmim-amarelo. As estacas foram confeccionadas com aproximadamente $5 \mathrm{~cm}$ de comprimento e 2 folhas apicais, sendo desinfestadas numa solução de hipoclorito de sódio $(0,5 \%)$ por 15 minutos. Em seguida, nas bases das estacas foram aplicadas diferentes concentrações de AIB na forma de talco, conforme os seguintes tratamentos 0, 1000 e $2000 \mathrm{mg} \mathrm{Kg}^{-1}$. As estacas foram plantadas em tubetes contendo vermiculita de granulometria média e acondicionadas em casa de vegetação $\left(24^{\circ} \mathrm{C} \pm 2^{\circ} \mathrm{C}\right.$, UR $\left.=90 \%\right)$ do Setor de Ciências Biológicas da UFPR, no verão. Após 48 dias constatou-se que houve um elevado número de estacas enraizadas de jasmim-amarelo (90 a 95,7\%). Para variável comprimento médio das raízes por estaca, os tratamentos com AIB estimularam o crescimento das raízes diferindo estatisticamente do tratamento controle. Com base nos resultados encontrados, conclui-se que o jasmim-amarelo é uma espécie que apresenta uma elevada capacidade de enraizamento, com taxas acima de $90 \%$ no verão, podendo ser considerada de fácil enraizamento.

Palavras-chave: espécie ornamental, auxina, enraizamento, AIB.

\begin{abstract}
The yellow jasmine (Jasminum mesnyi Hance) belonging to the family Oleaceae, is a semi-herbaceous shrub, with yellow and very fragrant flowers, appear in abundance in spring. Because of the potential ornamental yellow jasmine (Jasminum mesnyi Hance - Oleaceae) this study aimed to evaluate the optimal concentration of indole butyric acid (IBA) to induce rooting of softwood cuttings. The cuttings were made with about $5 \mathrm{~cm}$ long and 2 apical leaves, and disinfected in a solution of sodium hypochlorite $(0.5 \%)$ for 15 minutes. Then, on the bases of cuttings were applied different concentrations of IBA in the form of powder, according to the following treatments 0,1000 and $2000 \mathrm{mg} \mathrm{Kg}^{-1}$. The cuttings were planted in conical polyethylene container with vermiculite of medium granulometry and placed in a greenhouse $\left(24^{\circ} \mathrm{C} \pm 2^{\circ} \mathrm{C}, \mathrm{RH}=90 \%\right)$ of the Department of Biological Sciences, UFPR. After 48 days it was found that there were a high number of rooted cuttings of jasmine yellow (90 to $95.7 \%$ ). For variable length of roots per cutting treatments with IBA stimulated root growth were significantly different than control treatment. Based on these results, we conclude that the yellow jasmine is a species that has a high rooting capacity, with rates above $90 \%$ in summer, can be considered easy to root.
\end{abstract}

Keywords: ornamental plant, auxin, rooting, IBA

\footnotetext{
${ }^{1}$ Bióloga, M. Sc., Professora da Faculdade Assis Gurgacz - FAG, Curso de Ciências Biológicas, Avenida das Torres n. 500, CEP: 85.806-095, Bairro Santa Cruz, Cascavel, PR. claudiacruz@fag.edu.br

${ }^{2}$ Bióloga, M. Sc., fernandafanti@gmail.com

${ }^{3}$ Bióloga, Pós-Doutora, Departamento de Botânica, Setor de Ciências Biológicas, Universidade Federal do Paraná (UFPR), Curitiba, PR, Brasil. E-mail: kazu@ufpr.br
} 


\section{INTRODUÇÃO}

O jasmim-amarelo (Jasminum mesnyi Hance), pertencente à família Oleaceae, é um arbusto de estrutura semi-herbácea originário da China. Apresenta caráter escandente com caules finos, muito flexíveis e densamente ramificados. As flores aparecem em abundância na primavera, mas se fazem presentes o ano todo, são amarelas e podem ser singelas ou dobradas, bastante perfumadas. $\mathrm{Na}$ antiguidade, suas flores eram utilizadas no Japão para aromatizar o chá preto. $\mathrm{Na}$ atualidade, é mais utilizada como cerca viva. É cultivado de preferência em locais altos para permitir a formação pendente da ramagem, não sendo, portanto, conduzido como trepadeira (Lorenzi \& Souza, 1999).

A reprodução dessa espécie se dá principalmente por meio da estaquia caulinar (Lorenzi \& Souza, 1999), tipo de propagação que vem sendo largamente utilizada, uma vez que a planta originada desse processo mantém as características selecionadas das plantas parentais (Ono et al., 1994a). Segundo Hartmann et al. (2011) a propagação por estacas é a mais importante forma de clonagem de plantas, sejam elas ornamentais ou frutíferas. A propagação vegetativa pode proporcionar a formação de grande quantidade de mudas de boa qualidade em curto espaço de tempo (Fonseca et al., 1991).

Quando uma planta é considerada relativamente difícil de enraizar, pode-se tentar reverter esse obstáculo empregando reguladores vegetais, especificamente do grupo das auxinas, que além de estimularem e acelerarem o enraizamento das estacas, uniformizam e induzem a formação de raízes (Ono et al., 1994b), com consequente diminuição da permanência das estacas no leito de enraizamento (Ono et al., 1994a; Andrade \& Martins, 2003).

As principais auxinas utilizadas para a indução do enraizamento são o ácido naftaleno acético (ANA) e o ácido indolbutírico (AIB), sendo o AIB mais utilizado por possuir alta atividade (Nass et al., 2001; Ono et al., 1998). Podem ser empregadas na forma de talco, na forma de solução aquosa ou dissolvida em solventes orgânicos como o álcool. Seu uso na forma de talco é de maior facilidade e praticidade para o produtor, sendo também de menor custo (Ono et al., 1994b).

Zuffellato-Ribas \& Rodrigues (2001) confirmam essa informação dizendo que em numerosas plantas, o enraizamento é grandemente aumentado pela adição de auxinas sintéticas, sendo o regulador vegetal de maior sucesso o AIB, por ser uma substância mais estável, menos solúvel que o AIA (ácido indolacético), considerado um dos melhores estimuladores de enraizamento. Segundo Jarvis et al. (1983) para se obter o máximo do efeito da auxina, esta deve ser fornecida em altas concentrações exógenas. O AIB apresenta como vantagens a baixa toxicidade, ação mais localizada do que os outros produtos e maior estabilidade química no corpo da estaca (Stumpf et al., 2001).

Embora o enraizamento de estacas seja influenciado por auxinas, estas não são as únicas substâncias envolvidas no processo; outros compostos como carboidratos e substâncias transportáveis produzidas nas folhas e gemas das estacas também são importantes (Zuffellato-Ribas \& Rodrigues, 2001); Biasi, 2002; Fatores mesológicos como luz, temperatura, umidade e oxigênio, desempenham um importante papel no enraizamento (Zuffellato-Ribas \& Rodrigues, 2001; Carvalho, 2002).

Apesar da grande utilização ornamental do jasmim-amarelo, há pouca informação sobre a produção de mudas desta espécie. Desta forma, este trabalho objetivou verificar a promoção do enraizamento em estacas caulinares de Jasminum mesnyi Hance sob a influência da aplicação de ácido indolbutírico (AIB) aplicado em diferentes concentrações.

\section{MATERIAL E MÉTODOS}

O presente trabalho foi conduzido em casa de vegetação climatizada $\left(24^{\circ} \mathrm{C} \pm 2{ }^{\circ} \mathrm{C}\right.$, com nebulização intermitente e umidade relativa (UR) do ar em torno de $90 \%$, localizada no Centro Politécnico, Setor de Ciências Biológicas, Universidade Federal do Paraná (UFPR), em Curitiba - Paraná.

Para obtenção das estacas, foram coletados ramos herbáceos de jasmim-amarelo (Jasminum mesnyi Hance) nas primeiras horas da manhã, no verão, nos jardins do Centro Politécnico. Os ramos coletados foram acondicionados em saco plástico e transportados até o Departamento de Botânica.

As estacas foram confeccionadas com corte basal em bisel e corte reto a $1 \mathrm{~cm}$ da última gema apical, mantendo-as com um comprimento de aproximadamente $5 \mathrm{~cm}$, sendo deixadas duas folhas na porção apical. Em seguida foram desinfestadas com solução de hipoclorito de sódio a $0,5 \%$ por 15 minutos, sendo posteriormente lavadas em água corrente por 5 minutos para posterior tratamento com o regulador vegetal.

Para as estacas de jasmim-amarelo, utilizouse ácido indolbutírico (AIB) na forma de talco em diferentes concentrações: T1: $0 \mathrm{mg} \mathrm{Kg}^{-1}$, T2: 1000 $\mathrm{mg} \mathrm{Kg}^{-1}$, T3 $2000 \mathrm{mg} \mathrm{Kg}^{-1}$.

As estacas foram plantadas em tubetes levemente cônicos, com capacidade de $53 \mathrm{~cm}^{3}$, utilizando vermiculita de granulometria média como substrato e acondicionadas na casa de vegetação. Após 48 dias do plantio, foram avaliadas as seguintes variáveis: estacas enraizadas; número médio de raízes por estaca; comprimento médio das 3 maiores raízes; estacas mortas; estacas que permaneceram vivas sem enraizar e formar calo e formação de calo.

O delineamento experimental adotado foi o inteiramente casualizado, com 3 tratamentos, 7 repetições e 10 estacas por unidade experimental, totalizando 210 estacas. Para análise dos dados foi empregado o programa estatístico JMP ("Statistical Analysis System" SAS Institute Inc. E.U.A., 19892000) versão 4.0, sendo utilizado o teste de Tukey ao nível de $5 \%$ de probabilidade. 


\section{RESULTADOS E DISCUSSÃO}

Após 48 dias de cultivo constatou-se que houve um elevado número de estacas de jasmimamarelo (Jasminum mesnyi Hance) enraizadas, o tratamento testemunha apresentou maior porcentagem de enraizamento $(95,7 \%)$ com relação a estacas tratadas com $1000 \mathrm{mg} \mathrm{Kg}^{-1}$ e $2000 \mathrm{mg} \mathrm{Kg}^{-1}$ de
AIB, ambos com $90 \%$ de enraizamento, sendo os resultados considerados satisfatórios mesmo na ausência de AIB (Tabela 1). O elevado enraizamento na testemunha indica que a espécie não necessita do uso de reguladores vegetais, podendo ser considerada uma espécie de fácil enraizamento (Cezar et al., 2009).

TABELA 1 - Média das porcentagens de enraizamento, número de raízes por estaca, comprimento das raízes e mortalidade de estacas de jasmim-amarelo (Jasminum mesnyi Hance) submetidas ao tratamento com ácido indolbutírico (AIB).

\begin{tabular}{lrrrrc}
\hline Tratamentos & EE (\%) ns & \multicolumn{1}{c}{ NR ns } & CM (cm) & EM (\%) & EV (\%) ns \\
\hline $0 \mathrm{mg} \mathrm{Kg}^{-1}$ AlB & 95,7 & 12,3 & $3,14 \mathrm{~b}$ & $0 \mathrm{~b}$ & 4,3 \\
$1000 \mathrm{mg} \mathrm{Kg}^{-1}$ AIB & 90,0 & 11,1 & $6,26 \mathrm{a}$ & $5,7 \mathrm{a}$ & 4,3 \\
$2000 \mathrm{mg} \mathrm{Kg}^{-1}$ AlB & 90,0 & 10,6 & $5,60 \mathrm{a}$ & $4,3 \mathrm{a}$ & 5,7
\end{tabular}

Nota: ns: não significativo. Médias seguidas por letra diferente na coluna diferem estatisticamente para teste de Tukey ao nível de $5 \%$ de probabilidade. AIB: ácido indolbutírico; EE: estacas enraizadas; NR: número de raízes por estaca; CM: comprimento médio das três maiores raízes; EM: estacas mortas; EV: estacas vivas que não enraizaram e não formaram calo.

Semelhantemente Althaus et al. (2004) em experimento com jasmim-amarelo utilizando ácido naftaleno acético (ANA), outra auxina sintética, obtiveram melhor resultado com a testemunha com $100 \%$ de enraizamento, seguido de $97,5 \%$ para a concentração de $5000 \mathrm{mg} \mathrm{Kg}^{-1}$ de ANA. Resultados similares foram encontrados por Ziantonio et al. (2003), os quais verificaram que na ausência de AIB, estacas de espinheira-santa apresentaram melhores resultados na porcentagem de enraizamento $(66,7 \%)$ e por Macanhão et al. (2003) em estacas de cipó-de-são-joão, que apresentaram $34,4 \%$.

Em estudos com utilização de AIB em estacas de duas espécies de caliandra, (Calliandra brevipes e Calliandra tweedii), foi verificado que o AIB não influenciou o enraizamento de $C$. brevipes, ao contrário de $C$. tweedii, na qual se elevou a porcentagem de enraizamento em relação à testemunha com a aplicação exógena de $2000 \mathrm{mg} \mathrm{L}^{-1}$ de AIB (Mayer et al., 2008).

No experimento de estaquia com manacá (Brunfelsia uniflora (Pohl.) D. Don.), utilizando aplicação de AIB em talco e em solução, na primeira avaliação, aos 60 dias após a instalação do experimento, não houve diferença significativa para a variável porcentagem de estacas enraizadas, sendo a maior porcentagem de $10,0 \%$ para o controle em solução. Na segunda avaliação, 120 dias após instalação, observou-se um aumento na porcentagem de enraizamento $(41,94 \%)$ para o mesmo tratamento, sendo considerado a aplicação de AIB desnecessária, uma vez que não aumentou a indução de raízes e calos (Althaus-Ottmann et al., 2006).

Em testes para verificar o potencial de enraizamento de estacas herbáceas de diferentes cultivares de mirtilo (Vaccinium sp.), tratadas com AIB nas concentrações de $0,2500,5000$ e $7500 \mathrm{mg} \mathrm{L}^{-1}$, foi verificado que o uso do AIB não proporcionou estímulo na emissão de raízes adventícias
(Trevisan et al., 2008).

De acordo com Paes et al. (2006) uma vez que a testemunha enraizou satisfatoriamente sem a adição de auxina exógena, supõe-se que a síntese de IAA endógeno seja alta, fazendo a espécie ser classificada como de fácil enraizamento.

Entretanto, Costa Jr et al. (2003) relatam que no enraizamento de goiabeiras, a concentração de $2000 \mathrm{mg} \mathrm{L}^{-1}$ de AIB aumentou a porcentagem de enraizamento das cultivares. Para Oliveira et al. (2003) as porcentagens de enraizamento do pessegueiro obtidas com o uso do AIB, são em geral acima de $70 \%$, sendo consideradas satisfatórias. Zuffellato-Ribas \& Rodrigues (2001) afirmam que o objetivo de tratar estacas com reguladores vegetais é proporcionar uma maior porcentagem de enraizamento.

Para o número de raízes de estacas de jasmim-amarelo não foi observada diferença estatística significativa em relação aos diferentes tratamentos. Mesmo assim, o tratamento que proporcionou maior número médio de raízes foi a testemunha com 12,3 raízes por estaca, seguidos das estacas tratadas com $1000 \mathrm{mg} \mathrm{Kg}^{-1}$ e $2000 \mathrm{mg} \mathrm{Kg}^{-1}$ de AIB, com 11,1 e 10,6, respectivamente.

A utilização de $10000 \mathrm{mg} \mathrm{L}^{-1}$ de AIB induziu o número de raízes em estacas de jasmim-amarelo, atingindo a média de 19,4 raízes por estacas, ao passo que o controle formou na média 15,1 raízes por estaca (Lopes et al., 2000).

Ziantonio et al. (2003) em seu trabalho com espinheira-santa obteve maior número de raízes também na testemunha (5 raízes por estaca), Contraditoriamente, Andrade \& Martins (2003) obtiveram melhores resultados no número de raízes de porta-enxerto para citros quando usaram $400 \mathrm{mg} \mathrm{L}^{-1}$ de AIB.

Em testes de enraizamento com estacas de guaco (Mikania glomerata Spr.), o uso de diferentes concentrações de ANA em talco e em solução (0; 
CRUZ-SILVA C. T. A., et al. Propagação vegetativa...

2500; $5000 \mathrm{mg} \mathrm{kg}^{-1}$ e 0; 2500; $5000 \mathrm{mg} \mathrm{L}^{-1}$, respectivamente), apresentaram taxa de enraizamento foi alta $(\sim 90 \%)$ em todos os tratamentos, destacandose o tratamento na concentração de $2500 \mathrm{mg} \mathrm{kg}^{-1}$ de ANA em forma de talco pra indução de maior número de raízes por estaca (Colodi et al., 2008).

Para a variável comprimento médio das raízes de estacas de jasmim-amarelo o tratamento com AIB estimulou o comprimento das estacas, sendo 6,26 e $5,60 \mathrm{~cm}$ para as tratadas com 1000 $\mathrm{mg} \mathrm{Kg}^{-1}$ e $2000 \mathrm{mg} \mathrm{Kg}^{-1}$ de AIB, respectivamente. O tratamento controle apresentou uma média de comprimento das raízes de $3,14 \mathrm{~cm}$. Observando que a variável comprimento médio das 3 maiores raízes (cm) não apresentou diferença estatisticamente significativa entre as dosagens de auxina, supõe-se que o aumento na concentração de AIB não tenha influência no comprimento das raízes de jasmimamarelo, podendo sugerir a utilização da dosagem mais baixa (1000 $\mathrm{mg} \mathrm{Kg}^{-1}$ ).

Estacas de jasmim-amarelo tratadas com ANA na concentração de $5000 \mathrm{mg} \mathrm{Kg}^{-1}$ tiveram seu crescimento incrementado quando comparado ao controle (Althaus et al., 2007). O uso de ANA em ramos semi-lenhosos de (Abelia x grandiflora Hort. ex. L. H. Bailey) não aumentou a taxa de enraizamento comparada ao controle, mas na concentração de $5000 \mathrm{mg} \mathrm{Kg}^{-1}$ também aumentou o número de raízes por estaca e o comprimento das três maiores raízes (Paes et al., 2006).

Bujokas et al. (2003) em trabalho com pingode-ouro (Duranta repens) não encontraram valores estatísticos diferentes para o comprimento médio das raízes tratadas com AIB. Pimenta et al. (2003) trabalhando com hortência, utilizaram AIB e ANA nas estacas, embora não tenham encontrado diferenças estatisticamente significativas, os autores relatam que houve uma diferenciação no uso de AIB aumentando o comprimento médio das três maiores raízes.

Loner et al. (2010) verificaram que não houve contribuição do AIB no enraizamento de estacas herbáceas de azaleia (Rhododendron simsii Planch), o qual não influenciou também o comprimento médio da raiz, numero de folhas por estaca e massa fresca das estacas.

Para a taxa de mortalidade, o tratamento testemunha apresentou resultados superiores aos demais tratamentos, pois foi nulo o número de estacas mortas. Os tratamento com $1000 \mathrm{mg} \mathrm{Kg}^{-1} \mathrm{e}$ $2000 \mathrm{mg} \mathrm{Kg}^{-1}$ de AIB apresentaram 5,7 e 4,3\% de mortalidade, respectivamente, sendo para propagação vegetativa esses valores considerados baixos. Andrade \& Martins (2003) analisando a porcentagem de sobrevivência de porta-enxerto para citros, também observaram que para a testemunha o índice de mortalidade foi menor em relação aos demais tratamentos com AIB.

As estacas de jasmim-amarelo não apresentaram formação de calos. Frazon et al. (2004) observaram uma pequena porcentagem de formação de calos na base das estacas de goiabeira-serrana (Acca sellowiana Berg.), de 0 a $5 \%$, sem diferença estatística significativa entre os diferentes tratamentos com AlB e estacas de 12 e $18 \mathrm{~cm}$ de comprimento. Segundo Fachinello et al. (1995) o calo aparece quando os tecidos do floema e xilema são lesionados, o que resulta em posterior formação de um tecido de cicatrização, constituído por um aglomerado de células desorganizadas, parenquimatosas e em diferentes etapas de lignificação. Hartmann et al. (2011) relatam que as raízes aparecem frequentemente após a formação de calos, como também podem ser processos independentes em função das condições endógenas da estaca e do ambiente no qual se desenvolve. Zuffellato-Ribas \& Rodrigues (2001) citam que em vários casos, a formação do calo e a formação da raiz são independentes umas das outras, fato confirmado por trabalhos com resultados divergentes.

Como a taxa de enraizamento foi alta, as estacas de jasmim-amarelo apresentaram baixo percentual de estacas que permaneceram vivas sem enraizar, de 4,3 a 5,7\%, não havendo diferença significativa para as estacas tratadas com AlB quando comparadas ao controle (Tabela 1). De forma semelhante, para a porcentagem de estacas vivas não enraizadas de espinheira-santa (Maytenus ilicifolia Martius ex Reissek) não houve diferença estatística significativa quando avaliado o enraizamento em diferentes substratos e concentrações de ANA (Lima et al., 2008).

\section{CONCLUSÕES}

Com base nos resultados encontrados no presente trabalho, conclui-se que o jasmim-amarelo é uma espécie que apresenta uma elevada capacidade de enraizamento, com taxas acima de $90 \%$ no verão, sem a aplicação de AIB, podendo ser considerada de fácil enraizamento. Entretanto, com o uso de AIB há um aumento no comprimento das raízes.

\section{REFERÊNCIAS}

1. ALTHAUS, M. M.; LEAL, L.; SILVEIRA, F.; ZUFFELLATO-RIBAS, K. C.; RIBAS, L. L. F. Estaquia de Jasmim-amarelo (Jasminum mesnyi Hance) utilizando diferentes substratos e ácido naftaleno acético. In: Anais do $55^{\circ}$ Congresso Nacional de Botânica e $26^{\circ}$ Encontro Regional de Botânicos de MG, BA e ES. Anais... Livro de Resumos Sociedade Botânica do Brasil Universidade Federal de Viçosa - UFV, 2004. v. CD ROM, 2004.

2. ALTHAUS, M . M.; LEAL, L.; SILVEIRA, F.; ZUFFELLATO-RIBAS, K. C.; RIBAS, L. L. F. Influência do ácido naftaleno acético e dois tipos de substrato no enraizamento de estacas de jasmim-amarelo. Revista Ciência Agronômica, Fortaleza, v.38, n.3, p.322-326, 2007. 
CRUZ-SILVA C. T. A., et al. Propagação vegetativa...

3. ALTHAUS-OTTMANN, M. M.; LEAL, L.; ZUFFELLATOORIBAS, K. C. Propagação vegetativa de manacá (Brunfelsia uniflora (Pohl.) D. Don). Revista Brasileira de Horticultura Ornamental, v. 12, n.1, p. 31-36, 2006.

4. ANDRADE, R. A.; MARTINS. A. B. G. Propagação vegetativa de porta-enxertos para citros. Revista Brasileira Fruticultura, v. 25, n.1, 2003.

5. BIASI, L. A. Reguladores de crescimento vegetal. In: WACHOWCZ, C. M.; CARVALHO. R. I. N. Fisiología Vegetal, produção e pós-colheita. Editora Champagnat: Curitiba, 2002.

6. BUJOKAS, W. M.; CRUZ-SILVA, C. T. A.; ZUFFELLATO-RIBAS, K. C. Propagação vegetativa de Duranta repens L. via estaquia pela aplicação de auxinas sintéticas. Cultura Agronômica, v.12, n.1, p.117-124, 2003.

7. CARVALHO, R. I. N. Fisiologia de produção de espécies frutíferas. In: WACHOWCZ, C. M.; CARVALHO. R. I. N. Fisiologia Vegetal, produção e pós-colheita. Editora Champagnat: Curitiba, 2002.

8. CEZAR, T. M.; SOUZA, F. C.; MACIEL, R. T.; DEMBISKI, W.; ZUFFELLATO-RIBAS, K. C.; RIBAS, L. L. F.; KOEHLER, H. S. Estaquia e alporquia de Tibouchina fothergillae (D.C.) Cogn. (Melastomataceae) com a aplicação de ácido naftaleno Acético. Scientia Agraria, Curitiba, v.10, n.6, p.463-468, 2009.

9. COLODI, F. G.; RAMOS, N. L. C.; ZUFFELLATO-RIBAS, K. C.; RIBAS, L. L. F.; KOEHLER, H. S. Propagação vegetativa de guaco com adição de ácido naftalenoacético. Scientia Agraria, v.9, n.1, p.95-98, 2008.

10. COSTA JR., W. H.; SCARPARE FILHO, J. A.; BASTOS, D. C. Estiolamento da planta matriz e uso de ácido indolbutírico no enraizamento de estacas de goiabeiras. Revista Brasileira Fruticultura, v. 25, n.2., p. 301-304, 2003.

11. FACHINELLO, J. C.; HOFFMAN, A.; NACHTIGAL, J. C.; KERSTEN, E.; FORTES, G. R. Propagação de plantas frutíferas de clima temperado. 2.ed. Pelotas: UFPEL, 1995. 179 p.

12. FONSECA, C. E. L.; SPERANDIO, J. P.; CORREA, M. P. F.; BUENO, D. M.; LIMA, R. Propagação vegetativa do Jacarandá-da-Baía através da estaquia. Pesquisa Agropecuária Brasileira, v. 26, n.1, p. 31-37, 1991.

13. FRAZON, R. C.; ANTUNES, L. E. C.; RASEIRA, M. C. B. Efeito do AIB e de diferentes tipos de estaca na propagação vegetativa da goiabeira-serrana (Acca sellowiana Berg). Revista Brasileira de Agrociência, v.10, n. 4, p. 515-518, 2004.

14. HARTMANN, H. T.; KESTER, D. E.; DAVIES JR, R. T.; GENEVE, R. L. Plant Propagation: principles and practices. 8. ed. New Jersey: Prentice Hall, 2011.

15. JARVIS, B. C.; ALI, A. H. N.; SHAHEED, A. I. Auxin and boron in relation to the rooting response and ageing of mung bean cuttings. New phytologist, Cambridge, v. 95, p.509-518, 1983.

16. LIMA, D. M.; SILVA, C. L.; RITTER, M.; BIASI, L. A.; ZANETTE, F.; ZUFFELLATO-RIBAS, K. C. Substratos e auxinas no enraizamento de estacas caulinares de espinheira-santa. Scientia Agraria, v.9, n.1, p.85 $-89,2008$.

17. LONER, A. B.; UNEMOTO, L. K.; YAMAMOTO, L. Y.; COSTA, L.; SCHNITZER, J. A.; SATO, A. J.; RICCE, W. S.; ASSIS, A. M.; ROBERTO, S. R. Enraizamento de estacas de azaleia (Rhododendron simsii Planch.) no outono em AIB e diferentes substratos. Ciência Rural, Santa Maria, v.40, n.8, p.1720-1725, 2010.

18. LOPES, M. F.; JACOB, A. P.; BETTENCOURT, J. M. Estudos para a propagação vegetativa de algumas ornamentais de exterior. In: III Encontro Nacional de Plantas Ornamentais / Associação Portuguesa de Horticultura. Lisboa : APH, 2000: 173-177.

19. LORENZI, H.; SOUZA, H. M. Plantas ornamentais no Brasil: arbustivas, herbáceas e trepadeiras. 3. ed. Nova Odessa:Instituto Plantarum, 1999. 818p.

20. MACANHÃO, P.; ZUFFELLATO-RIBAS, K. C.; CARPANEZZI, A. A.; TAVARES, F. R. Enraizamento do cipó-de-são-joão (Pyrostegia venusta) pela aplicação de IBA e NAA. Brazilian Journal of Plant Physiology, Campinas, v. 15, supl., p. 132, 2003. Edição de Resumos do Congresso Brasileiro de Fisiologia Vegetal, 9, 2003. Atibaia, SP.

21. MAYER, J. L. S.; CARDOSO, N. A.; CUQUEL, F.; BONA, C. Formação de raízes em estacas de duas espécies de Calliandra (Leguminosae - Mimosoideae). Rodriguésia, v.59, n.3, p.487-495, 2008.

22. NASS, L. L.; VALOIS, A. C. C.; MELO, I. S.; VALADARES-INGLIS, M. C. Recursos genéticos e melhoramento Plantas. Rondonópolis: Fundação MT, 2001. 1183p

23. OLIVEIRA, A. P.; NIENOW, A. A.; CALVETE, E. O. Capacidade de enraizamento de estacas semilenhosas e lenhosas de cultivares de pessegueiro tratadas com AIB. Revista Brasileira de Fruticultura, v. 25, n. 2, p. 282-285, 2003.

24. ONO, E. O.; RODRIGUES, J. D.; PINHO, S. Z. Ação de auxinas e/ou boro, no processo de formação de raízes em estacas de café (Coffea arabica L. CV. "Mundo Novo"). Arquivos Biologia e Tecnologia, v.37, n.1, p. 157-166, 1994a.

25. ONO, E. O.; BARROS, S. A.; RODRIGUES, J. D.; PINHO, S. Z. Enraizamento de estacas de Platanus acerifolia tratadas com auxinas. Pesquisa Agropecuária Brasileira, v.29, n.9, p.1373-1380, 1994b.

26. ONO, E. O.; RODRIGUES, J. D.; PINHO, S. Z. Efeito de auxinas e boro no enraizamento de estacas caulinares de kiwi retiradas em diferentes épocas. Pesquisa Agropecuária Brasileira, v. 33, n.2., p. 213219, 1998. 
CRUZ-SILVA C. T. A., et al. Propagação vegetativa...

27. PAES, E. G. B.; HÖGER FILHO, G.; ZUFFELLATO-RIBAS, K. C.; BRITO, F. P. Estaquia de Abelia x grandiflora Hort. Ex L. H. Bailey. Cultura agronômica, v.15, n.1, p.26-36, 2006.

28. PIMENTA, A. C.; PINTO, L. S.; ZUFFELLATO-RIBAS, K. C. Enraizamento de hortênsia pela aplicação de auxinas comerciais. Cultura Agronômica, v.12, n.1, p.1-8, 2003.

29. STUMPF, E. R. T.; GROLLI, P. R.; SCZEPANSKI, P. H. G. Efeito do ácido indolbutírico, substrato e tipo de estaca no enraizamento de Chamaecyparis lawsoniana PARL. Revista Brasileira de Agrociência, v.7, n. 2., p. 101-105, 2001.

30. TREVISAN, R.; FRANZON, R. C.; NETO, R. F.; GONCALVES, R. S.; GONCALVES, E. D.; ANTUNES, L. E. C. Enraizamento de estacas herbáceas de mirtilo: influência da lesão na base e do ácido indolbutírico. Ciência e Agrotecnologia, v. 32, n. 2, p. 402-406, 2008.

31. ZIANTONIO, V. L. F.; LIMA, J. G.; ZUFFELLATO-RIBAS, K. C.; RIBAS, L. L. F. Propagação vegetativa de Maytenus iliciofolia Mart. Utilizando diferentes concentrações de ácido indol butírico (IBA). Brazilian Journal of Plant Physiology, Campinas, v. 15, supl., p. 139, 2003. Edição de Resumos do Congresso Brasileiro de Fisiologia Vegetal, 9, 2003. Atibaia, SP.

32. ZUFFELLATO-RIBAS, K. C.; RODRIGUES, J. D. Estaquia: uma abordagem dos principias aspectos fisiológicos. 1.ed. Katia Christina Zuffellato Ribas: Curitiba, 2001. 39p

Recebido em 06/12/02011

Aceito em 05/08/2013 